\title{
Climate Scenarios:
}

What we need to know and how to generate them 

Working Paper No. 45

\section{Climate Scenarios:}

What we need to know and how to generate them

Heru Santoso

Monica Idinoba

Pablo Imbach

December 2008 


\section{Contact}

\section{Heru Santoso}

Center for International Forestry Research (CIFOR)

P.O. Box 0113 BOCBD

Bogor 16000

Indonesia

Tel: +62 2518622622

Fax: +62 2518622100

Email: h.santoso@cgiar.org

Cover photo by Meria Azis

\section{Acknowledgements}

The authors thank peers who reviewed earlier drafts of this report: Bruno Locatelli and Armi Susandi.

\section{Disclaimers}

The views expressed in this publication are those of the author(s) and not necessarily those of CIFOR.

This document has been produced with the financial assistance of the European Union (EuropeAid/ENV/200481719). The contents of this document can under no circumstances be regarded as reflecting the position of the European Union. 


\section{Table of contents}

Summary

1 Introduction $\quad 5$

2 Do we need climate scenarios for adaptation? 6

3 What climate data do we need?

4 What are the different types of climate scenarios? 9

5 Which emission scenarios should be used? 11

6 Which GCM to choose? 12

7 How to modify the spatial resolution of climate data? 14

8 How to modify the temporal resolution of climate data? 16

9 How to deal with uncertainties? 17

10 Can we assess extreme events?

11 Where to find additional information? 20

12 Conclusions 22

References

$\begin{array}{ll}\text { Glossary } & 25\end{array}$ 


\section{Summary}

Climate change profoundly affects the natural and social environment. Decision-makers and resource managers require information regarding future changes in climate average and variability to better anticipate potential impacts of climate change.

This book provides some overviews on the roles of climate scenarios in adaptation planning and what should be considered in using and generating climate scenarios, in a frequently ask questions style. Specifically, this book tries to answer questions commonly addressed by non-climatologists when they want to address climate scenario in adaptation plans. It covers topics on the need of climate scenarios for adaptation, types of climate data or information we need, different types of climate scenarios, emission scenarios, choosing general circulation model (GCM), how to modify the spatial and temporal resolution of climate data, how to deal with uncertainties, and the progress of the climate models in assessing extreme events. The book also provides additional information regarding tools and sources of data in relation to climate scenario. 


\section{Introduction}

C imate change profoundly affects the natural and social environment. For example, changes in seasonal to interannual climate strongly affect agricultural production, the quantity and quality of water resources, and resources coming from land and marine ecosystems. IPCC (2007b) indicates several key impacts on different sectors that are correlated with climate change such as freshwater resources and their management; ecosystems; food, fibre and forest products; coastal systems and low lying areas; industry, settlement and society; and health.

Decision-makers and resource managers require information regarding future changes in climate average and variability to better anticipate potential impacts of climate change. However, future climate patterns are difficult to predict (Goodess 2000). In particular, the future radiative forcing from greenhouse gases is difficult to quantify because the emissions of these gases depend on many assumptions and uncertain factors such as population growth, the use of carbon fuel as an energy source, technological development, economic development, policy and attitudes towards environment, etc (see Nakićenović et al. 2000; IPCCTGICA 2007). For this reason, climate scenarios have been developed to investigate the potential consequences of anthropogenic climate change. Therefore, a climate scenario differs from a climate prediction or forecast (IPCC 2007a) ${ }^{1}$. Climate science in this context has contributed significantly to the understanding of current changes and the projection of long-term future changes in climate that result from both natural and human influences (IPCC 2007b).

Climate scenarios, which often serve as input to impact models, are commonly constructed through projections. These projections are the response of the climate system to emission scenarios of greenhouse gases and aerosols. There are variety of models to simulate future climate (Cotton and Pielke 1995) that contain embedded assumptions. Long-term projections beyond the 2050s heavily depend on these models and simulations, because the compositions of anthropogenic elements that affect the climate (eg greenhouse gas concentration, land cover condition, demographic composition and distribution, socio-economic conditions etc) are different from the current and near future compositions.

This book discusses some roles of climate scenarios in adaptation planning, and what should be considered in using and generating climate scenarios, in a 'frequently asked questions' style. Specifically, this book tries to answer questions commonly addressed by non-climatologists, such as adaptation practitioners, policymakers and resource managers, when they want to address climate scenario in adaptation plans. 


\section{Do we need climate scenarios for adaptation?}

Dessai et al. (2005) discussed the role of climate scenarios in three different types of adaptation approaches. They are the IPCC approach, human development approach, and risk approach. This section summarises each approach in the context of whether the climate scenario is needed or not.

\section{IPCC approach}

IPCC approach follows a traditional approach of impact assessment in which using climate scenario is an important step towards adaptation planning (Dessai et al. 2005). In the case of adaptation programme in the multinational Mekong river basin in South East $\mathrm{Asia}^{2}$, for example, a highly quantitative impact assessment through modelling was employed to estimate the possible implications of climate and land cover changes for water resources and the dependent sectors (agriculture, freshwater fisheries, aquatic habitat), and for the livelihood of the communities. High quality climate scenario information plays a central role in determining who or what is vulnerable and how to enhance the adaptive capacity for the vulnerable sectors and communities.

\section{Human development approach}

Human development approaches argue that steps to improve present levels and types of adaptation to reduce present vulnerability are essential to overcoming impacts of climate change in the future (Dessai et al. 2005). This approach considers that vulnerability is driven by both climatic and non-climatic stresses. The focus of adaptation is on existing climatic hazards and on factors that determine adaptive capacity including availability of financial resources (wealth); availability of technology and skilful persons to utilise it effectively; access to information; and the existence of legal, social and organisational arrangements. Adaptation options are largely drawn from successful experience that community or system possesses in coping with past and/or ongoing climatic stresses. A synthesis from a case of adaptation in Sudan, coping with drought, showed that the key to future adaptation planning is the capability to ensure that favourable factors and conditions in the past are maintained or improved. Climate scenarios in this case are irrelevant.

The weakness of this approach is the assumption that the future vulnerability is similar to current vulnerability (Dessai et al. 2005). Adaptation plans based on this assumption may be inadequate or irrelevant in the future if characteristics of climate in the future are substantially different from those under the present conditions. This approach is, therefore, less appropriate if used for designing a long-term adaptation plan.

\section{Risk approach}

Risk assessment is part of a risk management process to reduce risk to human health and to ecosystems. Central to risk assessment is the management of uncertainties, which allows the risk of a potentially disastrous event to be determined and reduced (Dessai et al. 2005).

Climate scenarios are used as a tool to assess the relationship between climate change and the event, and to identify the impact thresholds to be analysed for risk. In this approach climate scenarios are not the centre of the assessment, but they can support threshold identification, uncertainty quantification and planning action to reduce risk.

\section{Adaptation Policy Framework}

The Adaptation Policy Framework (APF) considers adaptation as a continuum from current to future in which current vulnerability and future climate change risk are characterised as a continuous process (Burton et al. 2002). It is addressed here, because this framework appears to link the human development approach and the risk approach. In this framework, climate scenarios are useful in characterising future climate risks and for evaluating the performance of adaptation options in a risk assessment ( Nakićenović et al. 2000; Dessai et al. 2008), and for decision makers to systematically assess the performance and robustness of their adaptation strategies over a wide range of plausible future states of climate and many other factors. Highly accurate climate scenarios in such cases are not necessarily as a key in the assessment process (Price and Flannigan 2000).

In summary, the role of climate scenario in adaptation planning may be relevant or irrelevant depending on the adaptation assessment approach. Climate scenarios tend to be irrelevant in a human development approach and highly relevant in the IPCC approach. In general, studies that focus on social vulnerability to climate change tend to examine vulnerability to current climate variability and therefore do not use climate scenarios. The risk approach is somewhere in between depending on the details to 
be identified. The APF uses climate scenarios for characterising future climate risk as part of a continuous process of adaptation. Spatial and temporal scales also influence the importance of climate scenario. Climate scenarios tend to be less important for current or shorter time scale adaptation and in a very localised area, but they tend to be relevant for a long-term adaptation and in large scale areas (global or regional). In most cases, anticipatory adaptation requires the best available information concerning the nature of future climate risks (SEI 2008). Several general recommendations have been proposed for future climate information to be useful in adaptation process, among them: improve access to historical climate data, for better quality of downscaling and examination of past climate trends; improve skills for applying climate science and for better use of climate change models, including techniques of downscaling; and improve communication between information producers and information users. 


\section{What climate data do we need?}

The climate data or climatological information required by impact analysts varies enormously depending on types of studies. Some factors to consider in using climate information, and relevant for base line and projected impact studies, are listed below. The list is extracted from the IPCC General Guidelines on the Use of Scenario Data for Climate Impact and Adaptation Assessment (IPCC-TGICA 2007).

- Variables: The climate variables required are dependent on the impact models used. The most common variables in impact studies are surface observations of air temperature and precipitation. Some impact models require a larger set of variables as input, such as solar radiation, humidity, windspeed, soil temperature and snow cover. Certain climate scenario construction procedures (eg statistical downscaling from general circulation model, or GCM, outputs) requires specific variables, such as daily air pressure data or mean sea-level pressure. Some indices may be useful for identifying important large-scale climatic variations such as the Southern Oscillation Index (related to El Niño events). Relative sea-level rise ${ }^{3}$ is useful for climate change impact assessment of coastal zones.

- Spatial scales: Spatial scale required depends on the objective of modelling and technical factors in the modelling such as the coverage area, quality of source data, and terrain condition (Price and Flannigan 2000). The required climate information or data may be for a single site (eg for assessing crop response to climate), a region (eg for modelling surface water distribution over a large water catchment), or the whole globe (eg for modelling changes in geographical life-zone distribution). If climate is significantly influenced by the terrain condition, finer resolution data depict climate better than coarse resolution data.

- Temporal resolution: Temporal resolution may range from annual through seasonal and monthly means to daily or hourly time steps. In some cases long-term averages may suffice (eg for mapping vegetation distribution) but in some impact studies daily time series are essential (eg for simulating land slide mechanism in relation to rainfall).

- Extreme events: Studies of disasters often require knowledge of the probabilistic distribution of extremes in a certain period of time and area at risk, usually for estimating the risk of climate related disasters such as storm surges, droughts and forest and land fires.

General circulation models (GCMs) try to mimic complex natural dynamic processes of climate and can produce a large number of variables (many of which are irrelevant for impact studies) and high temporal resolution (up to hourly). The spatial resolution of the GCMs is generally considered coarse for impact studies, which may require downscaling (discussed further in chapter 7). 


\section{What are the different types of climate scenarios?}

The Intergovernmental Panel on Climate Change - Task Group on Data and Scenario Support for Impact and Climate Assessment (IPCC-TGCIA) classified climatic scenarios into three main types (IPCC-TGICA 2007), based on how they are constructed. These are: synthetic scenarios, also known as incremental scenarios (IPCC 2001); analogue scenarios and climate model based scenarios.

\section{Synthetic scenarios}

The construction of synthetic scenarios or incremental scenarios involves a technique by which particular climatic elements are changed by a realistic arbitrary amount, for example, adjustment of temperature variable by $+1,+2$, and $+3^{\circ} \mathrm{C}$ from a reference state (baseline), or increase or reduction of precipitation by $5 \%, 10 \%$, and $15 \%$ from the baseline. The values of change may be kept constant for the whole year, or they may be changed monthly, seasonally, or interannually (IPCC-TGICA 2007).

This method has some advantages and disadvantages for climate change impact analyses. The main advantage of this method is that the climatic scenarios are easy to create and the results can be quickly obtained. The relative sensitivity of the object of study to the changes in climate can be quickly explored. The disadvantge of this method is that it does not present a realistic future climate due to its arbitrary nature. However, for the purpose of exploring relative sensitivity, and taking into account its ease of application and straightforward results, the synthetic scenarios method is still useful.

\section{Analogue scenario}

The analogue scenarios method involves an identification of the climate record that may represent the future climate condition of the region of interest. This can be done by a temporal analogue method, which method uses the past climate record as an analogue of possible future climate (eg Warrick 1984; Budyko 1989; Shabalova and Können 1995), or by a spatial analogue method, which uses present climate information from another region to represent the possible future climate as the analogue.
There are several drawbacks to this analogue method. The main disadvantage of the temporal analogue method is the use of the past climate record, particularly the paleoclimatic reconstruction, because the cause of climate change in the past is likely to be different from the cause of future climate change (ie the past climate change was not caused by anthropogenic greenhouse gases). Current climate change is very likely driven by the increase in the concentration of greenhouse gases (IPCC 2007b), and therefore the scenarios do not correctly represent the future climate. The disadvantage of using the spatial analogue lies in the fact that the location is geographically different and therefore cannot correctly represent the future local climate.

\section{Climate model-based scenarios}

These scenarios use outputs from GCMs for their construction, and they usually are constructed by adjusting a baseline climate (typically based on regional observations of climate over a reference period such as 1961-1990) by the absolute or proportional change between the simulated present and future climates (IPCC-TGICA 2007). Most recent impact studies have constructed scenarios on the bases of transient GCM coarse resolution outputs downscaled to the required scale.

GCMs are complex numerical climate models that represent the physical processes of the climate system in the atmosphere, ocean, cryosphere and land surface. They are the only credible tool currently available for simulating the response of the global climate system to increasing concentration of greenhouse gases (Cotton and Pielke 1995; Goodess 2000). With the latest Atmosphere-Ocean General Circulation Models (AOGCMs), the quantitative estimates of future climate change have gained confidence (Randal et al. 2007), and the ability to simulate extreme events has improved (see Box 1). Some AOGCMs can simulate important aspects of El Niño-Southern Oscillation (ENSO).

Downscaling techniques are important for impact studies that use GCM outputs and require finer resolution than the GCM's resolution. (See chapter 7.) 


\section{Box 1. Evolution of General Circulation Models}

Based on the evolution, general circulation models (GCMs) can be classified into three main types (Viner 2000) as follows.

- Atmospheric GCMs coupled with a simple slab ocean (ie a single fixed layer representation of ocean) and simple land-surface parameterisation schemes. Examples of these models are UKMO, UKHI, CCC, GFDL, and GISS, which represent an early generation of GCMs that perform future climate experiments based on an equilibrium response. With this method, the models evaluate the new stable state (equilibrium) of the global climate following an instantaneous increase of atmospheric gases, for example by doubling concentration of $\mathrm{CO}_{2}$ or its radiative equivalent of all greenhouse gases. The equilibrium-response experiments are considered unrealistic because the change in the $\mathrm{CO}_{2}$ concentration (or its radiative equivalent) in nature is gradual rather than sudden.

- Atmospheric GCMs coupled to a three-dimensional representation of the ocean system, in which ocean currents and heat transport are represented, and with simple land-surface parameterisation schemes, eg UKTR, ECHAM1, and GISSTR. These models perform transient-response experiments and are conducted with coupled atmosphere-ocean models (AOGCMs), which link dynamically detailed models of the ocean with those of the atmosphere. AOGCMs are able to simulate time lags between a given change in atmospheric composition (eg $1 \%$ change in $\mathrm{CO}_{2}$ concentration per year) and the response of climate (Carter and La Rovere 2001). Recent evaluation of impacts is based on scenarios formed from results of transient experiments as opposed to equilibrium experiments.

There are two kinds of transient response experiments, cold start and warm start. Cold start transient experiments do not take into account the historical forcing of rising greenhouse gases during the last century, but start the forcing from an assumed equilibrium at present. These cold start experiments may underestimate the actual change in climate for the first few decades of the experimental years. Warm start experiments take account of the historical forcing of rising greenhouse gases to avoid cold start problem.

- Atmospheric GCMs coupled to a three-dimensional representation of the ocean and a three-dimensional terrestrial biosphere model (aerosol experiments). Examples of the models are HadCM3, ECHAM4 and CSIRO-Mk2. Aerosols, which may be included in the model, may affect climate directly by scattering and absorbing solar radiation, which cool the surface temperature (ie negative radiative forcing), and indirectly by altering the properties and lifetime of the clouds. Similar to AOGCMSs, these models perform transient-response experiments. 


\section{Which emission scenarios should be used?}

The IPCC Special Report on Emissions Scenarios (SRES) in replacing the old IPCC scenarios (IS92) identifies 40 different scenarios following four families of story lines. Six illustrative scenarios were drawn from these four families: A1FI (fossil intensive), A1T (predominantly non fossil), A1B (balanced across energy sources), A2, B1 and B2 (Nakićenović et al. 2000) (see Box 2). All emission scenarios were designated as equally valid and probable (IPCC-TGICA 2007).
Impact analysts may use non-IPCC SRES scenarios for specific interests. For example, unavoidable scenario with greenhouse gas emission is at year 2000 level. This scenario is practically unattainable and therefore invalid. Fast growth scenario follows a story line by which practically no commitment is made to reduce the greenhouse gas emission. This represents a very high emission rate (ie $\mathrm{CO}_{2}$ to increase by more than $3 \%$ annually, higher than the highest IPCC SRES scenario).

\section{BoX 2. SRES scenarios}

SRES contains 40 scenarios that fall into four qualitative storylines (Nakićenović et al. 2000): A1, A2, B1and B2.

The A1 storyline describes a future world of very rapid economic growth, global population that peaks in the mid twentyfirst century and declines thereafter. The A1 family develops into three groups that describe alternative directions of technological change in the energy system. These three: A1FI is fossil intensive (highest), A1T is non-fossil energy sources (mid), and A1B is a balance across all sources (lowest).

The A2 storyline describes a very heterogeneous world. The global population increases continuously and the economic development is primarily regionally oriented and per capita economic growth is more fragmented and slower than in other families.

The B1 storyline describes a convergent world with the same global population that peaks in the mid twenty-first century and declines thereafter, as in the A1 family, but with rapid changes in economic structures toward a service and information economy, with reduction in material intensity, and the introduction of clean and resource-efficient technologies.

The $\mathbf{B} 2$ storyline describes a world in which the emphasis is on local solutions to economic, social, and environmental sustainability. The global population increase is at a lower rate than A2 family, intermediate levels of economic development, and less rapid and more diverse technological change than in the B1 and A1 families. The scenario is oriented towards environmental protection but it focuses on local and regional levels. 


\section{Which GCM to choose?}

GCMs are run by a number of centres. Some differences exist among the models, which result in various climate sensitivities ${ }^{4}$ in a range likely between $2.0^{\circ} \mathrm{C}$ and $4.5^{\circ} \mathrm{C}$ with a best estimate value of $3.0^{\circ} \mathrm{C}$ (Solomon et al. 2007). For sensitivity analyses, it is often useful to consider the results of several models when constructing the scenarios. However, users may find selecting appropriate models difficult especially when many models are available with various projection results (some models may show diverging results).

Some criteria for selecting climate models are suggested in Smith and Hulme (1998) and IPCCTGICA (2007):

- Vintage. Recent models are likely to be more reliable as they incorporated the latest knowledge in their construction.

- Resolution. Recent models tend to have finer resolution than older models. Higher resolution models contain more spatial details (eg complex topography, better-defined land-sea boundaries etc) and some key processes of climate variability such as ENSO events are better represented. However, finer resolution does not necessarily guarantee better model performance.
- Validity. Selection of models is based on how well they simulate present day climate. The validity of a model is assessed by comparing observed data with simulated data. The easy method is by 'upscaling' the observed data to a GCM grid size to compare it with the GCM simulated data. Statistical measures such as standard deviation, standard error, etc are useful for this analysis (Giorgi and Mearns 1991; Murphy et al. 2004).

- Representativeness of results. Preferably, results from more than one GCM are to be applied in an impact assessment. Selecting some representative GCM results helps in illustrating a range of changes in a key climate variable in the study region. For example, if a number of models show less annual precipitation, no change in precipitation and more annual precipitation, users can choose one for each cluster of the simulation results for illustrating future potential impacts of their studies.

A selection of climate data sets are available for public use from the IPCC Data Distribution Centre (DDC) (see Box 3) and WorldClim (see Box 4). The DDC also provides comprehensive guidelines for the use of the climate data, and links to more information including the SRES emission scenarios. 


\section{Box 3. IPCC Data Distribution Centre}

The following information has been extracted from IPCC-TGICA (2007).

IPCC Data Distribution Centre (DDC) was established in 1998, following a TGICA recommendation to facilitate the timely distribution of a consistent set of up-to-date scenarios of changes in climate and related environmental and socio-economic factors for use in climate impact and adaptation assessment.

The DDC is a shared operation between the British Atmospheric Data Centre in the UK, the Max-Plank Institute for Meteorology in Germany, and the Center for International Earth Science Information Network at Columbia University, New York, USA. It provides three main types of data and guidance, which meet certain criteria established by the TGICA. They are: socio-economic data and scenarios that follow the assumptions used for the construction of SRES emission scenarios (see Box 2); climate observations and scenarios; and data and scenarios for other environmental changes.

The climate observation data set contains $0.5^{\circ}$ latitude/longitude gridded monthly global land surface of 11 climate variables for the period 1901-2000 supplied by the Climatic Research Unit. The data set can be used to examine climate variability over the $20^{\text {th }}$ century, to evaluate the simulations of various GCMs over the period 1961-1990, and to combine observed data with GCM projections. The variables are precipitation and wet-day frequency; mean, maximum and minimum temperatures; vapour pressure and relative humidity; sunshine percent and cloud cover; frost frequency; and wind speed.

The monthly averaged results from climate change simulations by a number of climate modelling centres are also available. The results have been extracted from transient AOGCM simulations which include greenhouse gas only and combined greenhouse gas and sulphate aerosol forcings. Ensembles and time-slice experiments are also being provided. Main variables that are available are cloud cover, diurnal temperature range, precipitation, solar radiation, mean temperature, minimum temperature, vapour pressure, and wind speed.

IPCC TGICA apply some criteria for GCM experiment results could be placed at the DDC, which follows criteria set by Parry (2002). The climate models should

- be full 3D coupled ocean-atmospheric GCMs,

- be documented in the peer-reviewed literature,

- have performed a multi-century control run (for stability reasons) and

- have participated in the Second Coupled Model Inter-comparison Project (CMIP2).

- In addition, the models should

- have performed a $2 \times \mathrm{CO}_{2}$ mixed layer run,

- have participated in the Atmospheric Model Inter-comparison Project (AMIP),

- have a resolution of at least T40, R30 or $3^{\circ} \times 3^{\circ}$ latitude/longitude and

- consider explicit greenhouse gases (eg $\mathrm{CO}_{2}, \mathrm{CH}_{4}$ etc).

Comprehensive information about the DDC and the data it provides is available at http://www.ipcc-data/org.

\section{Box 4. WorldClim}

WorldClim provides projected climate data over the global land areas in geodetic coordinate system and in four different spatial resolutions; 30 seconds (about $0.86 \mathrm{~km}^{2}$ at the equator), 2.5 minutes, 5 minutes, and 10 minutes (about $344 \mathrm{~km}^{2}$ at the equator). Climate variables for download are monthly total precipitation, and monthly mean, minimum and maximum temperatures (and 19 derived bioclimatic variables), which are projected for years 2020, 2050 and 2080 derived from climate models of three different centres (CCCma, HadCM3 and CSIRO). The projections use emission scenarios A2 and B2.

The data have been produced with a simple downscaling technique. First, projected changes in a climate variable, which are the absolute or relative differences between the outputs of the GCM simulated baseline data (typically averaged data of 1960-1990) and the simulated target years (eg 2050), are developed. Then, these changes are interpolated to grid cells with 30 arc-second resolution. Finally, these high resolution changes are applied to interpolated observed climate data of current period (WorldClim data set) to get high resolution projected climate data of the target years.

WorlClim was developed by a team from the Museum of Vertebrate Zoology, University of California, Berkeley in collaboration with Centro International de Agricultura Tropical (CIAT) and The Cooperative Research Centre for Tropical Rainforest Ecology and Management. More information is available at http://www.worldclim.org/. 


\section{How to modify the spatial resolution of climate data?}

Selection of appropriate spatial resolutions in assessing impacts or ecosystem response to climate change depends on the objective of the modelling and accompanying technical factors (see also chapter 6 ). In general, finer resolution data are better than coarser ones for the purpose of database building to serve various studies and impact assessments of different scales, but finer resolution data need bigger data storage capacity than coarser data.

There are simple guidelines for handling the climate data in the context of spatial scale (Price and Flannigan 2000).

- It is easier to aggregate appropriately from fine resolution data than it is to interpolate (or disaggregate) from coarser data.

- Higher resolution enables more multivariate space of climate variables (temperature, precipitation, radiation, wind speed, humidity etc) to be sampled (in representing the field data), which in turn leads to more checks on model stability and robustness of output.

- Intercomparison of studies performed at different resolutions is easier if the climate data are derived from the same fine-scale data set.

- From 'end-user' point of view, it is more meaningful to get data with a relevant resolution that suits the user's objective.

Aggregating fine spatial resolution data to low resolution data (also known as upscaling) can be conducted with a simple process by calculating spatial average of the fine resolution data over the coarser grid size of interest. This can be done using a standard geographical information system or similar spatial information system.

Disaggregating coarse resolution to fine resolution (also known as downscaling or regionalisation) is more complex than upscaling. Downscaling is a common process when GCM output data is to be used for impact assessment at local level. However, the lack of skill in downscaling often limits the use of 'properly' downscaled data.

Recent GCMs have higher spatial resolution than older GCMs, which can be finer than $3^{\circ} \times 3^{\circ}$ latitude/ longitude. For some impact studies, direct use of original grid box information from GCM output may be appropriate. This is the simplest method of applying changes from GCM output in the impact studies. Cautions exist when using direct grid box information for an area smaller than the grid box size (von Storch et al. 1993): lack of confidence in regional estimates, at least four grid boxes should be used for the minimum effective spatial resolution; sites in close proximity to the box boundary may fall to different grid boxes, which results in wrong change information; a site on land may be represented as ocean due to coarse spatial resolution, which misleads the information because the climate response over land differs from that over ocean.

There are three main methods for obtaining regional detail from the coarse resolution of GCMs (Houghton et al. 2001; IPCC-TGICA 2007) that will be discussed in this chapter: simple interpolation, statistical downscaling and high-resolution dynamic modelling. The methods have also been reviewed in Carter and La Rovere (2001) and Houghton et al. (2001).

\section{Simple interpolation}

The simplest method of downscaling is to interpolate the change fields to the site or region of interest from nearby grid boxes and add these changes to the observed base-line data (eg Harrison et al. 1995; Neilson 1998). This overcome the problem of discontinuities in changing between adjacent sites in different grid boxes as discussed above, but at the same time introduces a false geographical precision to the estimates. The information coming from this method may be very similar to the coarse GCM patterns in general without additional determinants, such as terrain, for detailed spatial variation, and therefore may be misleading. However, because of its simplicity, this method is the most widely applied in scenario development (Houghton et al. 2001).

\section{Statistical downscaling}

The statistical downscaling methods generally involve two main steps. The first step is the development of statistical relationships between local climate variables (eg surface air temperature and precipitation) and largescale predictors. The next step is the application of such relationships to the output of GCM experiments in order to simulate local climate characteristics, with the assumption that these statistical relationships remain the same in the future. The statistical downscaling methods can be approached by a regression technique (Hewitson and Crane 1996; von Storch et al. 1993), a correlation with regional weather patterns using statistical methods such as neural-fuzzy system and Fourier transformation (eg Bárdossy et al. 1995; Denis et al. 2002; Terzi et al. 2006), and a stochastic weather generator (Markov chain) approach (Wilks 1992; Hughes and Guttorp 1994; Wilby et al. 1994). Of all these statistical methods, Wilby et al. (1998) found 
that the weather generator approach with a stochastic method produced the best result.

The statistical methods have an advantage in requiring less expensive computation than the highresolution dynamic model-based approach, which allows quick application to multiple GCMs. However, they have a major disadvantage in that they do not represent physical processes, and the internal relationships are kept fixed in the future. In addition, developing a statistical downscaling method will always require rather extensive observational data.

In contrast to the simple method, the statistical method can produce local climate changes that are different from the large-scale GCM estimates (Houghton et al. 2001) and better results for smaller and topographically complex regions such as the Alps, particularly when spatial and temporal coherence among a set of hourly weather variables is important (Price and Flannigan 2000).

\section{High resolution dynamic modelling}

Numerical dynamic models at high resolution over the region of interest can be used to obtain high resolution climate scenarios that can be grouped into three approaches (IPCC-TGICA 2007):

- A full GCM at a higher resolution for a limited number of years ('time slice' experiment)

- A full GCM at varying resolution across the globe with the highest resolution over the area of interest ('stretched grid' experiment) (Fox-Rabinovitz et al. 1997)

- A separate high resolution Limited Area Model (LAM) using GCM output to provide the boundary condition to control the simulation ('nesting' approach) (Giorgi et al. 1990; Giorgi and Mearns 1991). The LAM or nesting approach model is also known as regional climate model (RCM).
All these high resolution dynamic models are based on the same systems of physical equations used in GCMs, and are considered to best capture the complex atmospheric process (Price and Flannigan 2000).

The RCM has a typical spatial horizontal grid resolution in a range between 20 and $50 \mathrm{~km}$, and 100 to $1000 \mathrm{~m}$ vertical resolution. These high resolutions enable the model to represent some weather extremes and orographic effect precipitation. Like coarse-scale GCMs, this method requires heavy computation which limits the number of scenarios that can be performed (Goodess 2000; Carter and La Rovere 2001).

Like statistical methods which are completely dependent on the accuracy of regional climate patterns produced by GCM through static relationship, RCM is also dependent on GCM as the boundary conditions. Through higher resolution, however, RCM can better represent important physical processes than the statistical method, and can improve the physical realism of simulated regional circulation. On the other hand, the time slice and stretched grid GCM experiments are completely independent from GCM outputs (themselves are GCMs). These full GCM experiments are less commonly used because the spatial resolution of the outputs is still too coarse for many impact studies, and the temporal variability is poorly presented (Carter and La Rovere 2001).

The main disadvantage of the dynamic models is their complexity. Being highly computational they demand and require a long time to run the experiments.

The statistical method and RCM are among those commonly used for downscaling the GCM outputs for quality of representation (compared to simple interpolation method) (Houghton et al. 2001). Combining the two methods is common to produce very high resolution of climate scenarios and land atmosphere feedbacks (Zhang and Foufoula-Georgiou 1997). 


\section{How to modify the temporal resolution of climate data?}

Aggregating temporal resolution data, for example from daily to monthly is a straightforward process by calculating the average or sum of the fine resolution data over the coarse temporal resolution. Aggregating fine temporal resolution data into coarse resolution will lose important climate variation (eg daily variation of precipitation or daily maximum temperature) to be replaced by a single value of the sum or the average.

Disaggregating temporal resolution data, for example from annual data to monthly data or monthly to daily, is a more complex process. It is similar with a process to create synthetic data. Weather generator is a potential tool (and probably the only tool) to produce the synthetic data.
A weather generator is a statistical model used to generate various realistic synthetic daily sequences of weather or climate variables (see Box 5). Like other statistical models, weather generators require suitable observed data to derive the statistical relationship or properties. A large number of sequences can be generated with the same statistical properties as the original data (Markov chain) (IPCC-TGICA 2007). It can also be used for downscaling GCM outputs (see statistical downscaling in chapter 7).

\section{Box 5. Weather generators}

A weather generator produces synthetic time series of weather data of unlimited length for a location of interest based on the statistical characteristics of observed weather at that locations. Models for generating stochastic weather data are conventionally developed in two steps. The first step is to model daily precipitation and the second step is to model the remaining variables of interest, such as daily maximum and minimum temperature, solar radiation, humidity and wind speed conditional on precipitation occurrence (as the control). Different model parameters are usually required for each month, to reflect seasonal variations both in the values of the variables themselves and in their cross-correlations.

The use of weather generators is usually for one of the following reasons: long time series of daily weather are unavailable from observational record; data in the region of interest are sparse; gridded daily data for spatial impact analysis are not readily available; for change analysis in both the mean and inter-daily variability; and for model performance analysis or comparative analysis of the observed data with the simulated data. Weather generators can also be used for increasing temporal resolution or downscaling the coarse climate projection data. Those application of weather data require sufficient observational data for the construction of statistical properties that will be used for data generation. If weather generators are used to create weather time series representing a changed climate, climate change information is required.

Weather generator software is available for free as a component in the SDSM (see chapter 11, on Statistical Downscaling Model). 


\section{How to deal with uncertainties?}

Many climate scientists, science funding agencies and decision makers positioned climate scenarios as the core of adaptation, and reducing uncertainties in the climate projection is crucial (Murphy et al. 2004; MOHC 2007 in Dessai et al. 2008). Knowing the fact that the uncertainty cannot be separated from climate scenarios (see Box 6) has led to a tendency to quantify the uncertainties of climate scenario as a guide for effective adaptation strategies, especially if the climate scenario shows a range of possible future climates the region of interest may experience, which shifted the science in climate projections from deterministic climate to probabilistic (Dessai et al. 2008).

Having a wide range of plausible future climates is necessary to quantitatively analyse the uncertainty of the results. Techniques of ensembles ${ }^{5}$ or model intercomparisons resulting in a range of climate projections, for example, can be used to quantify the uncertainties or probabilistic aspect of climate scenarios. However, the climate projections to be analysed should be carefully selected, because they determine the outcome of a climate impact assessment (IPCC-TGICA 2007). Limitation in knowledge and randomness selection of climate scenarios may misrepresent uncertainty of the climate scenarios that may lead to maladaptation (Hall 2007). (See also chapter 6.)
Having a wide range of plausible future climates not only gives an advantage for uncertainty quantification, but also allows a shift in adaptation planning from using climate projections for impact studies to testing adaptation plan options using the representatives of a wide range of plausible future climates (Dessai et al. 2008) (see chapter 2, section on APF). With this approach, highly accurate climate data are unnecessary for adaptation planning (Price and Flannigan 2000). In other words, inaccuracy in climate data should not stop people from using them for adaptation programmes.

Despite uncertainties in climate projection, climate scenarios are important for picturing future climate and understanding its impacts. These uncertainties should not prevent the understanding of responses to plausible climate change (Price and Flannigan 2000).

The use of other scenarios (eg socio-economic scenarios) can be important for assessing future impacts and vulnerability to climate change (Füssel and Klein 2006; IPCC 2007b). Socio-economic scenarios have been less used, however, probably because of the difficulty in simulating socio-economic scenarios or their inherent uncertainties. 


\section{Box 6. Uncertainties of climate scenarios}

In general, the source of uncertainties of climate scenarios are multiple. The climate system itself is too complex to be represented in a numerical model and contains a number of assumptions and parameterisations that each climate modelling centres approaches differently.

There are several key uncertainties in climate projections that cause different results (IPCC 2007b; IPCC-TGICA 2007).

- Uncertainties in future greenhouse gas and aerosol emissions. Each scenario implies a different levels of atmospheric composition and hence of radiative forcing.

- Uncertainties in global climate sensitivity, due to differences in the way physical processes and feedbacks are simulated in different models. These create further uncertainties in:

" expected warming for a given $\mathrm{CO}_{2 \text {-eq }}$ stabilisation scenario.

$"$ emission trajectory required to achieve a particular stabilisation level.

" estimates of the strength of different feedbacks in the climate system, particularly cloud feedback, oceanic heat uptake, and carbon cycle feedback.

" aerosol impacts on the magnitude of the temperature response, clouds and precipitation.

- Future changes in the Greenland and Antarctic ice sheet mass, particularly due to changes in ice flow.

- Uncertainties surrounding regional projections of climate change, particularly precipitation that may give different results by different GCMs for the same mean global warming.

Climate model simulation of precipitation has improved over time but is still problematic, the most striking disagreements occurring in the tropics. In most models, the appearance of the Inter-Tropical Convergence Zone of cloudiness and rainfall in the equatorial Pacific is distorted, and rainfall in the Amazon Basin is substantially underestimated. Precipitation trends in the tropics are particularly uncertain.

From the modelling side, the order of increasing uncertainty is from changes in global temperature, changes in mean regional climate variables (temperature, precipitation etc), changes in seasonal regional climate variables and changes in climate variability such as ENSO and daily precipitation.

Mostly positive feedback loops that amplify the warming effect are not well understood and result in presenting models' tendency to underestimate the eventual equilibrium climate change for a given increase in atmospheric $\mathrm{CO}_{2}$ (Watson 2008). The uncertainty will start to decrease only as we actually observe what happens to climate in the future. 


\section{Can we assess extreme events?}

The link between natural climate variability and change with local and regional occurrence and severity of extreme events begins to disclose (Bader et al., 2008). Extreme events such as hurricane, floods, droughts and land and forest fires have enormous societal and environmental implications. Evidences exist to indicate that some natural climate variations, such as ENSO, are in connection with extreme events (Solomon et al. 2007).

Some GCMs can now simulate important aspects of ENSO, but there are still large uncertainties about their amplitudes and variability (Meehl et al. 2000; Meehl et al. 2007). What factors trigger the mechanism of this event is poorly understood (Cuny 2001). Simulation of the Madden-Julian Oscillation remains generally unsatisfactory (IPCC 2007b). Embedded high resolution models and global models $(9 \mathrm{~km}$ to $100 \mathrm{~km}$ grid spacing) can simulate tropical cyclones particularly in tropical South East Asia and South Asia, which bring extreme rainfall (Christensen et al. 2007). Better understanding of ENSO behaviour and the mechanisms of other climate variability under different climate condition (climate change) is needed to better assess the extreme events (Bader et al. 2008).

The challenge in simulating extreme events is to develop improved methods for modelling or downscaling climate information to the scales required for extreme event analysis (Solomon et al. 2007) and better understanding of the key climate variability processes. 


\section{Where to find additional information?}

The secretariat of the United Nations Framework Convention on Climate Change (UNFCC) produced the Compendium on Methods and Tools to Evaluate Impacts of, and Vulnerability and Adaptation to, Climate Change (UNFCCC Secretariat 2008). It provides key information on available frameworks, methods and tools, and their special features. It is designed to assist parties to the Convention and other potential users in selecting the most appropriate methodology for assessments of impacts and vulnerability, and preparing climate change adaptation. Parties are obligated by the Convention and various decisions of the Conference of the Parties to assess their national-level impacts of climate change and their efforts to adapt to these impacts, which have to be reported through their national communications. The compendium was developed in 1999 and updated in 2003, 2005 and most recently in 2008 .

The 2008 revision of the compendium was undertaken as part of the Nairobi Work Programme on impacts, vulnerability and adaptation to climate change in the work area of methods and tools. This work can contribute to efforts by parties and organizations to

- apply and develop methodologies and tools for impact, vulnerability and adaptation assessments;

- develop methodologies and tools for adaptation planning, measures and actions, and integration with sustainable development;

- disseminate existing and emerging methods and tools;

- facilitate the sharing of experiences and lessons learned on the use of those contained in the UNFCCC Compendium on methods and tools to evaluate impacts of, and vulnerability and adaptation to, climate change, including the assessment of costs and benefits.

The documents and techniques described in the UNFCCC Compendium on Methods and Tools address the development and use of scenario data in the vulnerability and adaptation assessment process. Several items listed in the compendium describe how to access data and guidance to support the development and application of scenarios.

Selected items below are relevant for the generation of, and access to, climate scenarios.

\section{The Climate Impacts LINK Project}

The Climate Impacts LINK Project provides output data from a large number of numerical climate models ad experiments from the Meteorological Office Hadley Centre, UK. The data, which come mainly from the global HadCM2, HadCM3 and HadGEM1 and regional HadRM2 and HadRM3 models, are available for use by the climate impact research community. The output data have global and regional coverage, and are available as daily and monthly average data sets of various climate variables commonly used for climate change studies. More information is available at http://badc.nerc.ac.uk/ data/link/.

\section{Statistical DownScaling Model (SDSM)}

SDSM is a user-friendly software package designed to implement downscaling methods to produce highresolution monthly climate information from coarseresolution GCM simulations. A weather generator component is embedded in the SDMS to produce multiple ensembles of synthetic daily weather sequences. SDSM can be used to generate fine-resolution (smallscale) climate scenarios, provided observational data and daily GCM outputs for large-scale climate variables are available. More information and the latest version of the software (SDSM 4.2.2) are available at https://co-public. lboro.ac.uk/cocwd/SDSM/ (users must register to access).

\section{MAGICC/SCENGEN}

MAGICC and SCENGEN are coupled, user-friendly interactive software packages that allow users to investigate future climate change and its uncertainties at both the global-mean and regional levels. MAGICC carries calculations at the global-mean level using the same upwelling-diffusion, energy-balance climate model that has been employed by IPCC. SCENGEN uses the results from MAGICC simulations, together with spatially detailed results from the archive of AOGCMs, to produce spatially detailed information on future changes in or absolute values of mean temperature, precipitation and mean sea level pressure, changes in their variability, and a range of other statistics, on a $2.5^{\circ}$ $\times 2.5^{\circ}$ grid resolution. Users can intervene in the design of global or regional climate change scenario by selecting and/or specifying the greenhouse gas and sulphur aerosol emissions scenarios, by defining the values for some climate model parameters that are important in determining the effects of uncertainties in the carbon cycle and the overall sensitivity of the climate system to external forcing, by specifying the preselected AOGCMs that are averaged to produce the climate change pattern information, and by selecting an area or region for spatial averaging of climate change results. More information and the latest version of the software package (MAGICC/ SCENGEN version 5.3.v2) are available at http://www. cgd.ucar.edu/cas/wigley/magicc/. 
Providing Regional Climates for Impact Studies (PRECIS)

PRECIS is a regional climate model constructed based on the Hadley Centre's regional climate modelling system HadRM3 (see chapter 7, on high resolution dynamic modelling). This model was developed to help generate high-resolution climate change scenarios for use in impact, vulnerability and adaptation studies. It runs on a personal computer with a simple user interface, so that experiments can easily be set up over any region in the world. Like any other regional climate model, PRECIS is driven by boundary conditions simulated by GCMs, which are forced by preselected SRES marker greenhouse gases emission scenarios. The current version (1.7) has boundary conditions simulated by GCM experiments from Hadley Centre (HadAM3P, HadCM3) and MaxPlank Institute (ECHAM5) that are supplied with the software. More information regarding this model is available at http:// precis.metoffice.com/. 


\section{Conclusions}

The role of climate scenarios in adaptation assessment and planning ranges from irrelevant to highly relevant depending on the approach, which is determined by nature of the case, scale of the area, climate data availability and capacity to handle them, and time scale.

If climate scenarios are available and reliable (ie they depict plausible future climate), they are always beneficial for picturing future climate and understanding its impacts. They are also useful, and probably more import, for testing the robustness of adaptation response or policies, despite their uncertainties.

Communicating climate scenario to users (decision makers, resource managers and planners etc) in a better way is a challenge. It will be more meaningful to describe the future climate condition in terms of likelihood of occurrences that can be assessed by quantifying the uncertainties. Consequently, there is a need to increase the capacity to better understand the climate change and climate scenario, and the skilful persons to downscale GCMs and handle the climate data in general.

GCMs are considered the best in depicting future climate driven by anthropogenic forcings, but they are too coarse for many impact studies. Treatments of the coarse scale GCM outputs before being used as inputs to many impact assessments and studies, in particular downscaling methods, affect the realism of the data. Choosing a downscaling technique is a tradeoff between many factors, among them the capability to illustrate realistic future climate, easiness to use and nature of climate information or data required for impact studies.

Several technical aspects in climate scenario constructions and handling have been briefly discussed. Useful tools and sources of data in relation to climate scenarios have also been described. 


\section{References}

Bader, D.C. et al. 2008 Climate models: an assessment of strengths and limitations. A Report by the U.S. Climate Change Science Program and the Subcommittee on Global Change Research. Department of Energy, Office of Biological and Environmental Research, Washington, D.C., USA. 124 pp.

Bárdossy, A., Duckstein, L. and Bogardi, I. 1995 Fuzzy rulebased classification of atmospheric circulation patterns. International Journal of Climatology 15: 1087-1097.

Budyko, M.I. 1989 Empirical estimates of imminent climatic changes. Soviet Meteorology and Hydrology 10 : 1-8.

Burton, I., Huq, S., Lim, B., Pilifosova, O. and Schipper, E.L. 2002 From impacts assessment to adaptation priorities: the shaping of adaptation policy. Climate Policy 2: 145159.

Carter, T.R. and La Rovere, E.L. 2001 Developing and applying scenarios. In: McCarthy, J.J., Canziani, O.F., Leary, N.A., Dokken, D.J. and White, K.S. (eds) Climate change 2001: impacts, adaptation, and vulnerability. Contribution of Working Group II to the third assessment report of the Intergovernmental Panel on Climate Change. Cambridge University Press, Cambridge, U.K.

Christensen, J.H. et al. 2007 Regional climate projections. In: Solomon, S. et al. (eds) Climate change 2007: the physical science basis. Contribution of Working Group I to the fourth assessment report of the Intergovernmental Panel on Climate Change. Cambridge University Press, Cambridge, UK and New York, USA.

Cotton, W.R. and Pielke, R.A. 1995 Human impacts on weather and climate. Cambridge University Press, Cambridge, UK. 288 pp.

Cuny, J.F. 2001 El Niño, a possible trigger mechanism. Journal of Theoretics, Commentary 3(5). http://www. journaloftheoretics.com/Articles/3-5/commentary3-5.htm (8 Apr. 2003).

Denis, B., Côté, J. and Laprise, R. 2002 Spectral decomposition of two-dimensional atmospheric fields on limited-area domains using the Discrete Cosine Transform (DCT). Monthly Weather Review 130: 1812-1829.

Dessai, S., Hulme, M., Lempert, R. and Pielke Jr., R. 2008 Climate predictions: a limit to adaptation? Living with climate change: are there limits to adaptation? Royal Geographical Society, London, pp. 49-57.

Dessai, S., Lu, X. and Risbey, J.S. 2005 On the role of climate scenarios for adaptation planning. Global Environmental Change 15: 87-97.

Fox-Rabinovitz, M.S., Stenchikov, G. and Takacs, L.L. 1997 A finite-difference GCM dynamical core with a variable resolution stretched grid. Monthly Weather Review 125: 2943-2961.
Füssel, H.-M. and Klein, R. 2006 Climate change vulnerability assessments: an evolution of conceptual thinking. Climatic Change 75(3): 301-329.

Giorgi, F., Marinucci, M.R. and Visconti, G. 1990 Use of a limited-are model nested in a general circulation model for regional climate simulation over Europe. Journal of Geophysics 95(D11): 18413-18431.

Giorgi, F. and Mearns, L.O. 1991 Approaches to the simulation of regional climate change: a review. Reviews of Geophysics 29: 191-216.

Goodess, C. 2000 Climate change scenarios. No. 9, Climatic Research Unit, University of East Anglia.

Hall, J. 2007 Probabilistic climate scenarios may misrepresent uncertainty and lead to bad adaptation decisions. Hydrological Processes 21: 1127-1129.

Harrison, P.A., Butterfield, R.E. and Downing, T.E. (eds.) 1995 Climate change and agriculture in Europe: assessments of impacts and adaptations. Research Report No. 9. University of Oxford, UK. 414 pp.

Hewitson, B.C. and Crane, R.G. 1996 Climate downscaling: techniques and application. Climate Research 7: 85-95.

Houghton, J.T. et al. (eds.) 2001 Climate Change 2001: the scientific basis. Contribution of Working Group I to the third assessment report of the Intergovernmental Panel on Climate Change. Cambridge University Press, Cambridge, UK.

Hughes, J.P. and Guttorp, P. 1994 A class of stochastic models for relating synoptic atmospheric patterns to regional phenomena. Water Resources Research 30(5): 1535-1546.

IPCC 2001 Climate change 2001: impacts, adaptation and vulnerability. Contribution of Working Group II to the third assessment report of the Intergovernmental Panel on Climate Change. Cambridge University Press, Cambridge, UK and New York, USA.

IPCC 2007a Climate change 2007: impacts, adaptation and vulnerability. Contribution of Working Group II to the fourth assessment report of the Intergovernmental Panel on Climate Change. Cambridge University Press, Cambridge, UK, 976 pp.

IPCC 2007b Climate change 2007: synthesis report. Contributions of Working Groups I, II and III to the fourth assessment report of the Intergovernmental Panel on Climate Change. IPCC, Geneva, Switzerland, 104 pp.

IPCC-TGICA 2007 General guidelines on the use of scenario data for climate impact and adaptation assessment. Version 2. Prepared by T.R. Carter on behalf of the Intergovernmental Panel on Climate Change, Task Group on Data and Scenario Support for Impact and Climate Assessment. 66 pp. 
Meehl, G.A. et al. 2000. Trends in extreme weather and climate events: issues related to modeling extremes in projections of future climate change. Bulletin of the American Meteorological Society, 81: 427-436.

Meehl, G.A. et al. 2007 Global climate projections. In: Solomon, S. et al. (eds.) Climate change 2007: the physical science basis. Contribution of Working Group I to the fourth assessment report of the Intergovernmental Panel on Climate Change. Cambridge University Press, Cambridge, UK and New York, USA.

MOHC 2007 Climate research at the Met Office Hadley Centre: Informing Government policy into the future, Met Office Hadley Centre, Exeter.

Murphy, J.M. et al. 2004 Quantification of modelling uncertainties in a large ensemble of climate change simulations. Nature 430: 768-772.

Nakićenović, N. et al. 2000 Emissions scenarios. A special report of Working Group III of the Intergovernmental Panel on Climate Change. Cambridge University Press, Cambridge, UK and New York, USA. 599 pp.

Neilson, R.P. 1998 Simulated changes in vegetation distribution under global warming. In: Watson, R.T., Zinyowera, M.C. and Moss, R.H. (eds.) The regional impacts of climate change: an assessment of vulnerability, 439-456. A Special Report of IPCC Working Group II. Cambridge University Press, Cambridge.

Parry, M.L. 2002 Scenarios for climate impact and adaptation assessment. Global Environmental Change 12: 149-153.

Price, D.T. and Flannigan, M.D. 2000 Modelling impacts of climate change on forests and forestry using climate scenarios. In: Cramer, W., Doherty, R., Hulme, M. and Viner, D. (eds.) Climate scenarios for agricultural and ecosystem impacts. Proceedings of the EU Concerted Action Initiative ECLAT-2 Workshop 2. Climatic Research Unit, Norwich, UK, Postdam, Germany, 13-15 October 2000.

Randal, D.A. et al. 2007 Climate Models and Their Evaluation. In: Solomon, S. et al. (eds.) Climate change 2007: the physical science basis. Contribution of Working Group I to the fourth assessment report of the Intergovernmental Panel on Climate Change. Cambridge University Press, Cambridge, UK and New York, USA.

SEI 2008 Effective use of climate science to improve adaptation in Africa. Policy Brief. Stockholm Environment Institute. 2p.

Shabalova, M.V. and Können, G.P. 1995 Climate change scenarios: comparisons of Paleoreconstructions with recent temperature changes. Climatic Change 29: 409-428.
Smith, J.B. and Hulme, M. 1998 Climate change scenarios. In: Feenstra, J.F., Burton, I. Smith, J.B. and Tol, R.S.J. (eds.) UNEP handbook on methods for climate change impact assessment and adaptation studies, 3-1-3-40. United Nations Environment Programme, Nairobi, Kenya and Institute for Environmental Studies, Amsterdam.

Solomon, S. et al. 2007 Technical summary. In: Solomon, S. et al. (eds.) Climate change 2007: the physical science basis. Contribution of Working Group I to the fourth assessment report of the Intergovernmental Panel on Climate Change. Cambridge University Press, Cambridge, UK and New York, USA.

Terzi, Ö., Keskin, M.E. and Taylan, E.D. 2006 Estimating evaporation using ANFIS. Journal of Irrigation and Drainage Engineering 132(5): 503-507.

UNFCCC Secretariat 2008 Compendium on methods and tools to evaluate impacts of, and vulnerability and adaptation to, climate change. With the services of: Erica Pinto, Robert C. Kay and Ailbhe Travers, CZM pty. Ltd., Stratus Consulting Inc. UNFCCC Secretariat.

Viner, D. 2000 Modelling climate change. Climatic Research Unit, University of East Anglia. http://www.cru.uea. ac.uk/cru/info/warming/ (18 Mar 2002).

von Storch, H., Zorita, E. and Cubasch, U. 1993 Downscaling of global climate change estimates to regional scales: an application to Iberian rainfall in wintertime. Journal of Climate 6: 1161-1171.

Warrick, R.A. 1984 The possible impacts on wheat production of a recurrence of the 1930s drought in the U.S. Great Plains. Climatic Change, 6: 5-26.

Watson, A.J. 2008 Certainty and uncertainty in climate change predictions: what use are climate models? Environmental Resource Economy, 39: 37-44.

Wilby, R., Greenfied, B. and Glenny, C. 1994 A coupled synoptic-hydrological model for climate change impact assessment. Journal of Hydrology 153: 265-290.

Wilby, R.L. et al. 1998 Statistical downscaling of general circulation model output: A comparison of methods. Water Resources Research 34(11): 2995-3008.

Wilks, D.S. 1992 Adapting stochastic weather generation algorithms for climate change studies. Climatic Change 22: 67-84.

Zhang, S. and Foufoula-Georgiou, E. 1997 Subgrid-scale rainfall variability and its effects on atmospheric and surface variable predictions. Journal of Geophysical Research 102(D16): 19559-19573. 


\section{Glossary}

The definitions in this glossary are extracted from Climate change 2007: impacts, adaptation and vulnerability. Contribution of Working Group II to the fourth assessment report of the Intergovernmental Panel on Climate Change (IPCC 2007a), unless the source is mentioned differently.

\section{Climate change}

Climate change is a change in climate over time, whether due to natural variability or as a result of human activity. The United Nations Framework Convention on Climate Change (UNFCCC) defines it as a change of climate as a result of human activity. See also climate variability.

\section{Climate change commitment}

The continuation process of change in climate and other future changes, such as extreme weather events and sea-level rise, even if the atmospheric composition was held fixed at today's values. The continuation is due to the thermal inertia of the ocean and slow processes in the biosphere, the cryosphere and land surfaces.

\section{Climate change scenario}

A climate change scenario is the difference between a climate scenario and the current climate.

\section{Climate scenario}

A plausible and simplified representation of the future climate, which is projected based on an internally consistent set of climatological relationships and assumptions of radiative forcing.

\section{Climate sensitivity}

The equilibrium increase of temperature as a result of a doubled concentration of $\mathrm{CO}_{2}$ above pre-industrial levels.

\section{Climate variability}

Climate variability refers to any statistical variations of the climate, such as the mean, standard deviations, statistics of extremes, etc on all temporal and spatial scales beyond that of individual weather events. See also climate change.

\section{Conference of the Parties (COP)}

COP is the supreme body of the Convention which meets once a year to review the Convention's progress in dealing with climate change. (http://unfccc.int/ essential_background/glossary/items/3666.php.)

\section{Convention}

See United Nations Framework Convention on Climate Change (UNFCCC)

\section{Data Distribution Centre (DDC)}

DDC was established in 1998 following a recommendation by the TGICA, to facilitate the timely distribution of a consistent set of up-to-date scenarios of changes in climate and related environmental and socio-economic factors for use in climate impact and adaptation assessment. The DDC is a shared operation between the British Atmospheric Data Centre in the UK, the Max-Plank Institute for Meteorology in Germany and the Center for International Earth Science Information Network at Columbia University, New York, USA. (IPCC-TGICA 2007.)

\section{El Niño-Southern Oscillation (ENSO)}

ENSO is a coupled atmosphere-ocean phenomenon of El Niño, which is a warm-water current that periodically flows along the coast of Ecuador and Peru, and the associated fluctuation of the inter-tropical surface pressure pattern and circulation in the Indian and Pacific Oceans, called the Southern Oscillation. This event has climatic effects throughout the Pacific region and in many other parts of the world. The opposite of an El Niño event is called La Niña.

\section{Eustatic sea level rise}

An increase in global average of sea level rise due to an increase in the volume of the world ocean. See also relative sea level rise.

\section{General circulation model (GCM )}

GCM is a numerical representation of the climate system based on the physical, chemical, and biological properties of its components, their interactions and feedback processes, and accounting for all or some of its known properties. GCM has evolved from simple to complex (see Box 1).

\section{Greenhouse gases}

Greenhouse gases are those gaseous constituents of the atmosphere that absorb and emit radiation at specific 
wavelengths within the spectrum of infrared radiation emitted by the Earth's surface, the atmosphere, and clouds. This property causes warming known as the greenhouse effect. Important greenhouse gases are: water vapour $\left(\mathrm{H}_{2} \mathrm{O}\right)$, carbon dioxide $\left(\mathrm{CO}_{2}\right)$, nitrous oxide $\left(\mathrm{N}_{2} \mathrm{O}\right)$, methane $\left(\mathrm{CH}_{4}\right)$, ozone $\left(\mathrm{O}_{3}\right)$, sulphur hexafluoride $\left(\mathrm{SF}_{6}\right)$, hydrofluorocarbons (HFCs) and perfluorocarbons (PFCs).

\section{Intergovernmental Panel on Climate Change (IPCC)}

IPCC was established in 1988 by the World Meteorological Organization and the UN Environment Programme, to survey world-wide scientific and technical literature. IPCC publishes assessment reports that are widely recognized as the most credible existing sources of information on climate change. The IPCC also works on methodologies and responds to specific requests from the Convention's subsidiary bodies, but it is independent of the Convention. (http://unfccc.int/ essential_background/glossary/items/3666.php.)

\section{Limited Area Model (LAM)}

See Regional Climate Model (RCM)

\section{Madden-Julian Oscillation (MJO)}

MJO is an intra-annual fluctuation that explains weather variations in the tropical region. This intraseasonal variations affect the seasonal monsoon patterns mainly in Asia and Australia. Each cycle of the oscillation lasts for 30 to 60 days and have been found to have some association with a global-scale feature of the tropical atmosphere. (http://www-das. uwyo. edu/ -geerts/cwx/notes/chap12/mjo.html.)

\section{Radiative forcing}

Radiative forcing is the change in the net vertical irradiance (in Watts per square meter) at the tropopause due to an internal or external change in the forcing of the climate system, such as a change in the concentration of $\mathrm{CO}_{2}$ or the solar radiation output.

\section{Regional Climate Model (RCM)}

A separate high resolution climate model simulated for a limited area, using GCM output as the boundary condition to control the simulation (known as a 'nesting' approach) (Giorgi et al. 1990).

\section{Relative sea level rise}

A local increase in the level of the ocean relative to the land, which might be due to ocean rise and/or land level subsidence. An area that undergoes a rapid landlevel uplift experiences a relative sea level drop.

\section{Risk}

The probability of harmful consequences, or expected losses (deaths, injuries, property, livelihoods, economic activity disrupted or environment damaged) resulting from interactions between natural or human-induced hazards and vulnerable conditions. (http://www.unisdr. org/eng/library/lib-terminology-eng\%20home.htm.)

\section{Scenario}

Scenario is a plausible description of how the future may develop, based on a coherent and internally consistent set of assumptions about driving forces and key relationships. Scenarios may be derived from projections, but are often based on additional information from other sources, sometimes combined with a story line.

\section{Sea level rise}

An increase in the mean level of the ocean. See also relative sea-level rise and eustatic sea-level rise.

\section{SRES}

The story lines and associated population, GDP and emissions scenarios associated with the Special Report on Emissions Scenarios (SRES) (Nakićenović et al. 2000), and the resulting climate change and sea-level rise scenarios. Four families of socio-economic scenario (A1, A2, B1 and B2) represent different world futures in two distinct dimensions: a focus on economic versus environmental concerns, and global versus regional development patterns (see Box 2).

\section{Story line}

A narrative description of a scenario (or a family of scenarios) highlighting the main scenario characteristics, relationships between key driving forces, and the dynamics of the scenarios (Nakićenović et al. 2000).

\section{Task Group on Data and Scenario Support for Impacts and Climate Analysis (TGICA)}

Previously known as Task Group on Scenarios for Climate and Impact Assessment (TGCIA), this task group was set up in 1996 with the mandate to facilitate wide availability of climate change related data and scenarios to enable research and sharing of information across the three IPCC working groups. Its activities, among others are to coordinate a Data Distribution Centre (DDC), to support IPCC work by identifying information needs in support of IPCC work, facilitating research on climate impacts, adaptation, and mitigation, and making related recommendations on cross-cutting issues. (http://www.ipcc-data.org/docs/ TGICA_Mandate_031207.htm.) 


\section{United Nations Framework Convention on Climate Change (UNFCCC)}

UNFCCC is an international environmental treaty produced at the United Nations Conference on Environment and Development (UNCED), informally known as the Earth Summit, held in Rio de Janeiro from 3 to 14 June 1992. It entered into force on 21 March 1994 after receiving ratifications of more than 50 countries. The treaty aims at stabilizing greenhouse gas concentrations in the atmosphere at a level that would prevent dangerous anthropogenic interference with the climate system. (http://unfccc.int/ essential_ background/convention/items/2627.php.) 




\section{Center for International Forestry Research (CIFOR)}

CIFOR advances human wellbeing, environmental conservation, and equity by conducting research to inform policies and practices that affect forests in developing countries. CIFOR is one of 15 centres within the Consultative Group on International Agricultural Research (CGIAR). CIFOR's headquarters are in Bogor, Indonesia. It also has offices in Asia, Africa and South America. CIFOR works in over 30 countries worldwide and has links with researchers in 50 international, regional and national organisations.

To request a copy of this publication, please contact cifor@cgiar.org

\section{www.cifor.cgiar.org}

